\title{
RESIDENTIAL EXPOSURE TO ENVIRONMENTAL TOBACCO SMOKE, AND ITS ASSOCIATES: FINDINGS FROM THE GLOBAL ADULT TOBACCO SURVEY IN POLAND
}

DOROTA KALETA ${ }^{1}$, PIOTR WOJTYSIAK ${ }^{2}$, BUKOLA USIDAME ${ }^{3}$, ELŻBIETA DZIANKOWSKA-ZABORSZCZYK ${ }^{4}$, ADAM FRONCZAK ${ }^{1}$, and TERESA MAKOWIEC-DĄBROWSKA ${ }^{5}$

\author{
${ }^{1}$ Medical University of Lodz, Łódź, Poland \\ Tobacco Control Department, Department of Preventive Medicine \\ ${ }^{2}$ County Office, Piotrków Trybunalski, Poland \\ ${ }^{3}$ University of Massachusetts, Boston, USA \\ Department of Public Policy \\ ${ }^{4}$ Medical University of Lodz, Łódź, Poland \\ Department of Social and Preventive Medicine \\ ${ }^{5}$ Nofer Institute of Occupational Medicine, Łódź, Poland \\ Department of Work Physiology and Ergonomics
}

\begin{abstract}
Objectives: Expanding the information on exposure to environmental tobacco smoke (ETS) at home and its associates is of great public health importance. The aim of the current analysis was to evaluate associates of exposure to environmental tobacco smoke among economically active male and female adults in Poland in their place of residence. Material and Methods: Data on the representative sample of 7840 adults from the Global Adult Tobacco Survey (GATS) carried out in Poland in the years 2009 and 2010 were applied. The Global Adult Tobacco Survey is a nationally representative household study. The logistic regression model was used for relevant calculations. Results: The exposure to environmental tobacco smoke in the place of living affected $59 \%$ of studied subjects. Out of non-smokers $42 \%$ of males and $46 \%$ females were exposed to the ETS in the at home. Increased risk of residential ETS exposure was associated with low education attainment, lack of awareness on adverse health consequences of second hand smoke (SHS), low level of support for tobacco control policies, living with a smoker. One of the factors associated with the ETS exposure was also the approval for smoking at home of both genders. The residential ETS exposure risk was the highest among males (odds ratio $(\mathrm{OR})=7.1,95 \%$ confidence interval $(\mathrm{CI}): 6.1-13.8, \mathrm{p}<0.001$ ) and females $(\mathrm{OR}=8.1,95 \%$ CI $6.5-11.8, \mathrm{p}<0.001)$ who declared that smoking was allowed in their place of residence compared to respondents who implemented smoking bans at their place of residence. Conclusions: Campaigns to decrease social acceptance of smoking and encourage adopting voluntary smoke-free rules at home might decrease the ETS exposure and reduce related risks to the health of the Polish population. Educational interventions to warn about adverse health effects of the ETS should be broadly implemented particularly in high risk subpopulations.
\end{abstract}

Key words:

Environmental tobacco smoke pollution, Involuntary smoking, Smoking, Tobacco control, Adults, Poland

Financial support was provided by the Bloomberg Initiative to Reduce Tobacco Use, a program of Bloomberg Philanthropies. Coordinator of the Global Adult Tobacco Survey (GATS) in Poland: Dorota Kaleta.

Received: August 20, 2014. Accepted: November 4, 2014.

Corresponding author: D. Kaleta, Medical University of Lodz, Department of Preventive Medicine, Żeligowskiego 7/9, 90-752 Łódź, Poland (e-mail: dkaleta@op.pl). 


\section{INTRODUCTION}

Chronic diseases are the leading causes of death, killing more than 36 million people globally on an annual basis [1]. Out of the 6 World Health Organization (WHO) regions, the European Region is the most affected, as chronic conditions cause $86 \%$ of deaths and $77 \%$ of the disease burden in the Region, thereby affecting health systems, economic development and well-being [2]. The majority of the diseases are largely preventable as they stem from a combination of non-modifiable risk factors, like age, sex and genetic make-up, as well as modifiable risk factors, such as poor diet, physical inactivity, tobacco use or alcohol use [1]. Tobacco is the single, largest avoidable health risk in the European Union (EU), accounting for nearly 700000 premature deaths each year [3].

The WHO European Region has one of the highest proportions of deaths attributable to tobacco, and despite considerable progress, the number of smokers in the EU is still high (28\% of the population) [3]. Many cancers, cardiovascular and respiratory diseases are linked to tobacco use [3]. However, the environmental tobacco smoke (ETS) exposure causes serious negative health consequences as well, out of which the increased risk of cardiovascular diseases, cancer, respiratory symptoms including lower respiratory tract infections, asthma and poor pregnancy outcomes appear to be most important [4,5]. Moreover, the ETS causes eye, throat and nasal irritations and many other adverse consequences that affect health and well-being. Considering the health consequences of the ETS exposure, most EU countries including Poland have introduced legislation to ban or limit smoking in public places and selected worksites inclusively [5,6]. The epidemiological studies have indicated a significant reduction in the level of exposure to the ETS in response to implementation of the smoking bans in work and public places [7]. Most studies have also indicated a significant reduction in respiratory and sensory symptoms. But exposure to tobacco smoke often occurs in private facilities and may substantially affect health of subjects also in their places of living. Most studies on this area were focused on the exposure to environmental tobacco smoke (ETS) in workplace or implemented in non-European countries. This topic is far less explored in European countries and there is a small number of data covering home exposure to the ETS and prevalence of smoking bans at home especially in Poland.

To diminish this gap in national statistics we evaluated associates of the exposure to environmental tobacco smoke at home among economically active adult males and females in Poland.

\section{MATERIAL AND METHODS}

\section{Study design and sample}

The Global Adult Tobacco Survey (GATS) was implemented in Poland in 2009-2010. The survey is the international project for systematically monitoring the use of tobacco products in the adult population. The Global Adult Tobacco Survey Poland is a nationally representative, standardized, household survey [8,9]. In Poland, the survey population selection process was based on multi-stage stratified geographically clustered sample of non-institutionalized population aged 15 years and older, including men and women. A sample of 14000 households was randomly selected. Out of the 14000 households selected for the survey, 8948 (63.9\%) households and 7840 (93.9\%) sampled persons successfully completed the interviews. The total survey response rate amounted to $65.1 \%$ [10]. Questionnaires were administered at respondents' homes during face-to-face interviews [11]. Further details on the GATS methodology and the overall approach are available in previously published reports [12].

\section{Study variables}

The individual GATS questionnaire is a comprehensive tool covering the characteristics of the study participants and a wide number of crucial features of tobacco use, 
including smoking tobacco products, use of smokeless tobacco, cessation, and secondhand smoke exposure.

A smoker was defined as a person who smokes regularly, on a daily basis or less frequently. The non-smoker group included former smokers and never smokers.

To determine the frequency of anyone smoking inside the respondent's home we culled from the question "How often does anyone smoke inside your home? Would you say daily, weekly, monthly, or less than monthly?.” Those who declared that tobacco is smoked in their house every day, at least once a week, or at least once a month we considered exposed to the ETS at home. Restrictions on smoking behavior at home were also studied. To determine whether smoking is allowed in the respondent's home, smoking rules at home were recorded in the following categories: smoking is allowed, smoking is prohibited - with some exceptions from this rule, smoking is completely prohibited, and no rules. This question referred to the rules inside the respondent's home, which only includes enclosed areas of the home. Areas outside home including patios, porches, etc. that are not fully enclosed were not taken into consideration. Moreover cohabitation with smoker(s) or non-smoker(s) was considered (living with a smoker, living with a non-smoker).

We classified our respondents as aware of the health consequences of the ETS (those who answered "yes" to the question: "Do you think that tobacco ETS causes serious diseases?") and not aware (those who answered "no" and "do not know").

In addition, we evaluated support for tobacco control policies among study subjects (high, medium, low).

\section{Socio-demographic variables}

Data on gender and age of the respondents was included in our analysis as well. Moreover, the data on educational attainment of respondents was taken into consideration. Educational level was classified as: primary education, vocational education, secondary education, and higher education. Measurement of job characteristics classified subjects as white-collar workers (management or co-management in a company or an enterprise; expert - independent professional with high qualifications and higher education; white-collar worker; administrative office staff in a company or an enterprise) and blue-collar workers (trade or services employee foreman, technician supervising manual workers, skilled worker, non-skilled worker). We also determined respondents' place of residence whether it was a rural or an urban area (urban area up to 50000 , from 50000 to 200000 , and over 200000 inhabitants).

\section{Statistical analyses}

Statistical associations of the particular categories of characteristics in the analyzed subgroups were assessed with the $\mathrm{Chi}^{2}$ test. All analyses were performed in 6 age groups: 15-19, 20-29, 30-39, 40-49, 50-59, 60 years and older. We used the logistic regression analysis to evaluate associates of exposure to the ETS at home. Initially, univariate coefficients - odds ratios (OR) of the impact of odd variables on the ETS exposure at home were calculated. Following, multifactorial analysis of the simultaneous effect of all statistically significant variables on the probability of the above risks was applied. For all analyses, $p$ values less than 0.05 were set as statistically significant. The calculation was completed based on statistical software package STATISTICA Windows XP version 8.0.

\section{RESULTS}

\section{Characteristics of the study population}

Out of the 14000 households chosen for the survey, 8948 (63.9\%) households and 7840 (93.9\%) sampled persons successfully completed the interviews. The overall survey participation rate amounted to $65.1 \%$ [8]. The data analyzed below covered 3696 economically active respondents including 2108 men and 950 women. From this population $58.8 \%$ of subjects declared being exposed to the ETS at home (females $59.8 \%$ vs. males $58 \%$, 
$\mathrm{p}>0.05)$. Of non-smokers $42.2 \%(\mathrm{~N}=514)$ males and $46.1 \%(\mathrm{~N}=499)$ females were exposed to the ETS in their place of living. Out of smokers $80.6 \%(\mathrm{~N}=717)$ males and $43.6 \%(\mathrm{~N}=451)$ females noticed the ETS in the past month. The rates of the ETS exposure in the place of residence differ among smokers and non-smokers by selected characteristics. The table 1 and 2 display characteristics of male and female exposed and not exposed to the ETS at home considering the smoking status of respondents. Total smoke-free rules at home were adopted by $37.1 \%(\mathrm{~N}=1373)$ of study participants.

\section{Associates of residual exposure to ETS Univariate analysis}

We calculated the odds ratios (OR) and 95\% confidence intervals (CI) for residential exposure to the ETS using the following variables: age, smoking status, place of residence, education, job classification, awareness of the ETS health consequences, level of support for tobacco control polices, cohabitation with a smoker, and smoking rules at home was tested in a logistic regression model.

In the univariate logistic regression, increased risk of the residential ETS exposure was associated with current smoker status, low education attainment, not perceiving the ETS as dangerous to health, low level of support for tobacco control policies, living with a smoker and lack of complete smoking ban at home, both male and female (Table 3). Age, job characteristics and rural or urban residence were not significantly associated with the ETS exposure at home.

\section{Multivariate analysis}

The multivariate section confirmed most of the results noticed in the univariate study except for smoking status (Table 3). After adjusting for statistically significant variables, a higher risk of the ETS at home was still observed among the males (approximately 2 times higher) and females (approximately 3 times higher) with primary and vocational education compared with subjects declaring higher education. The residential ETS was significantly correlated to the lack of awareness on adverse health consequences of the ETS in men $(\mathrm{OR}=2.6,95 \%$ CI: 1.7-3.9, p < 0.001) and in women $(\mathrm{OR}=4.0,95 \% \mathrm{CI}: 2.1-7.8, \mathrm{p}<0.001)$ as compared to respondents perceiving the ETS as dangerous to health. Furthermore, the significantly higher risk of the ETS was observed among male $(\mathrm{OR}=1.6,95 \% \mathrm{CI}$ : 1.1-2.6, $\mathrm{p}<0.05)$ and particularly female (OR $=2.7,95 \%$ CI: $1.2-$ $6.1, \mathrm{p}<0.05)$ cohabitating with a smoker or smokers as against those living with a non-smoker. In addition, low/medium level of support for tobacco control policies was associated with the residential ETS exposure. However, the strongest, single predictor of residential exposure to the ETS was the approval for smoking at home across both genders.

The residential ETS exposure risk was the highest among males $(\mathrm{OR}=7.1,95 \% \mathrm{CI}: 6.1-13.8, \mathrm{p}<0.001)$ and females $(\mathrm{OR}=8.1,95 \% \mathrm{CI} 6.5-11.8, \mathrm{p}<0.001)$ who declared that smoking was allowed as compared to respondents who implemented smoking ban at their places of residence. The lack of rules regarding smoking at home in the case of men and women also significantly increased the risk of the ETS. Age of respondents, job classification, smoking status and rural-urban residence were not associated with the residential ETS in the case of both genders.

\section{DISCUSSION}

In our study, we noticed a significantly higher prevalence of overall exposure to the ETS at home among economically active respondents than in the general Polish population (59\% vs. $44.2 \%, \mathrm{p}<0.01)$ [13]. This can be explained by the fact that the ETS exposure generally decreases with increasing age, with both males and females $\geq 65$ years of age showing the lowest prevalence, but our population covers younger, economically active age groups [13]. Moreover, a cross-country comparison of second hand smoke exposure among adults by King et. al showed that among all respondents, exposure to the ETS 












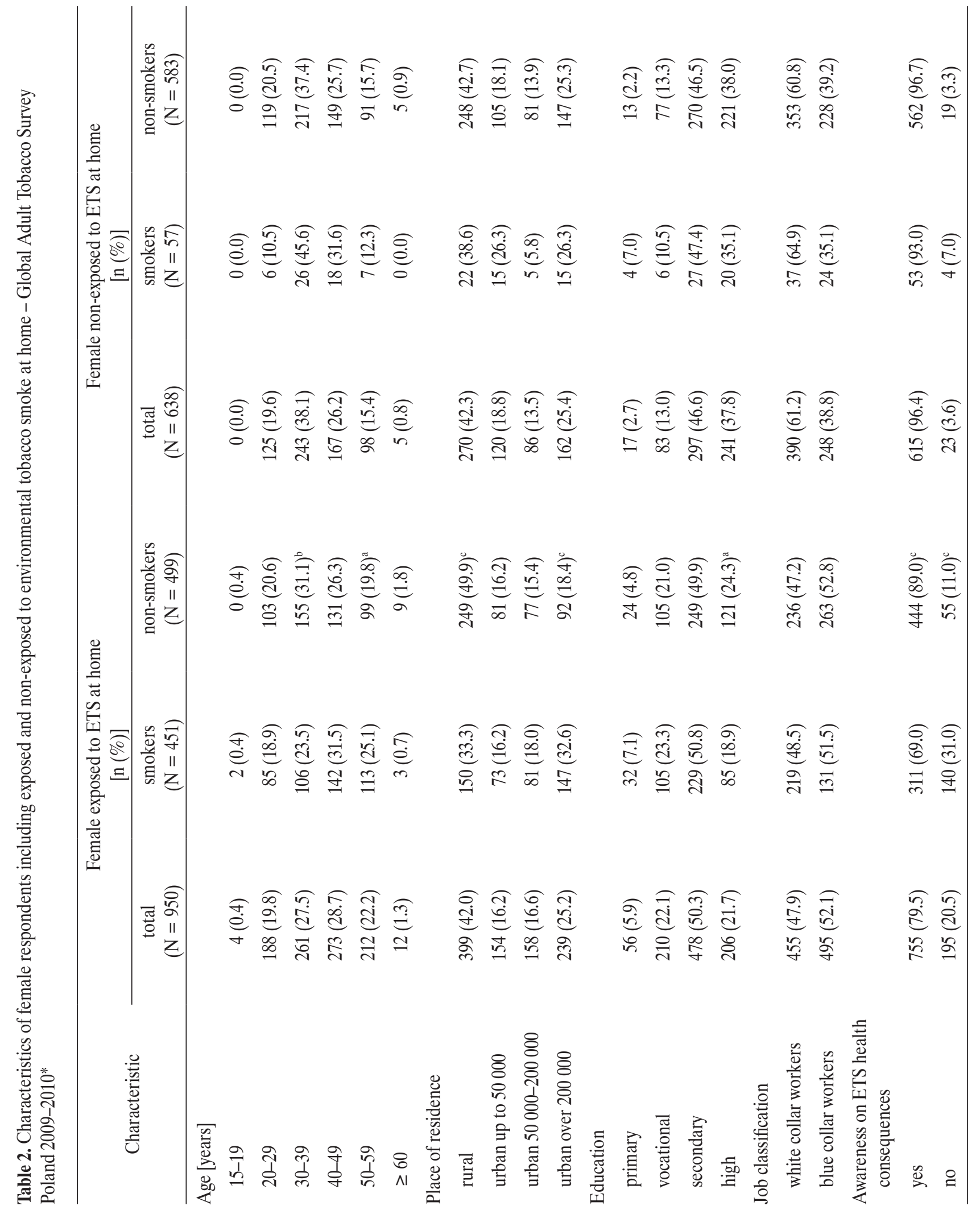




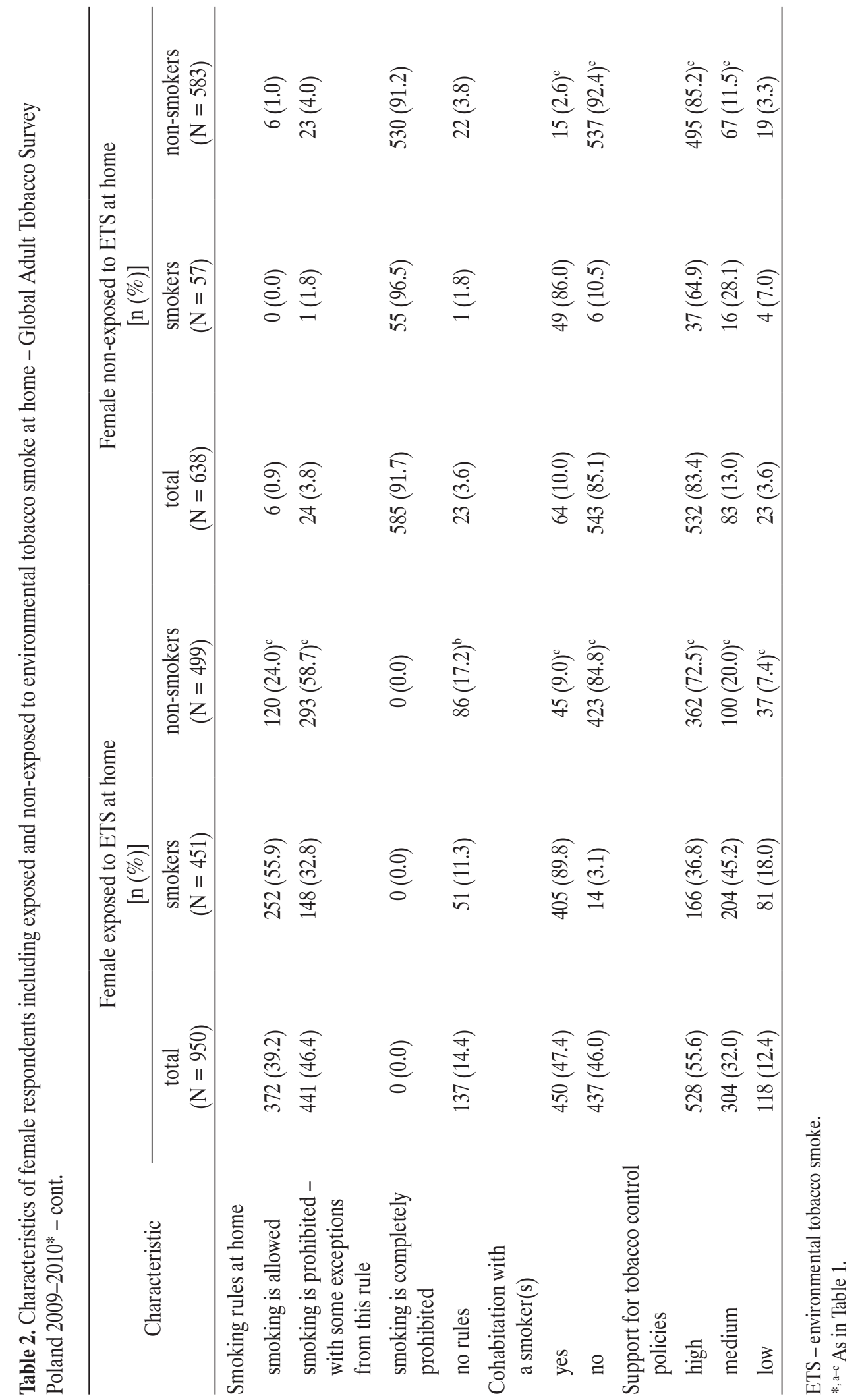




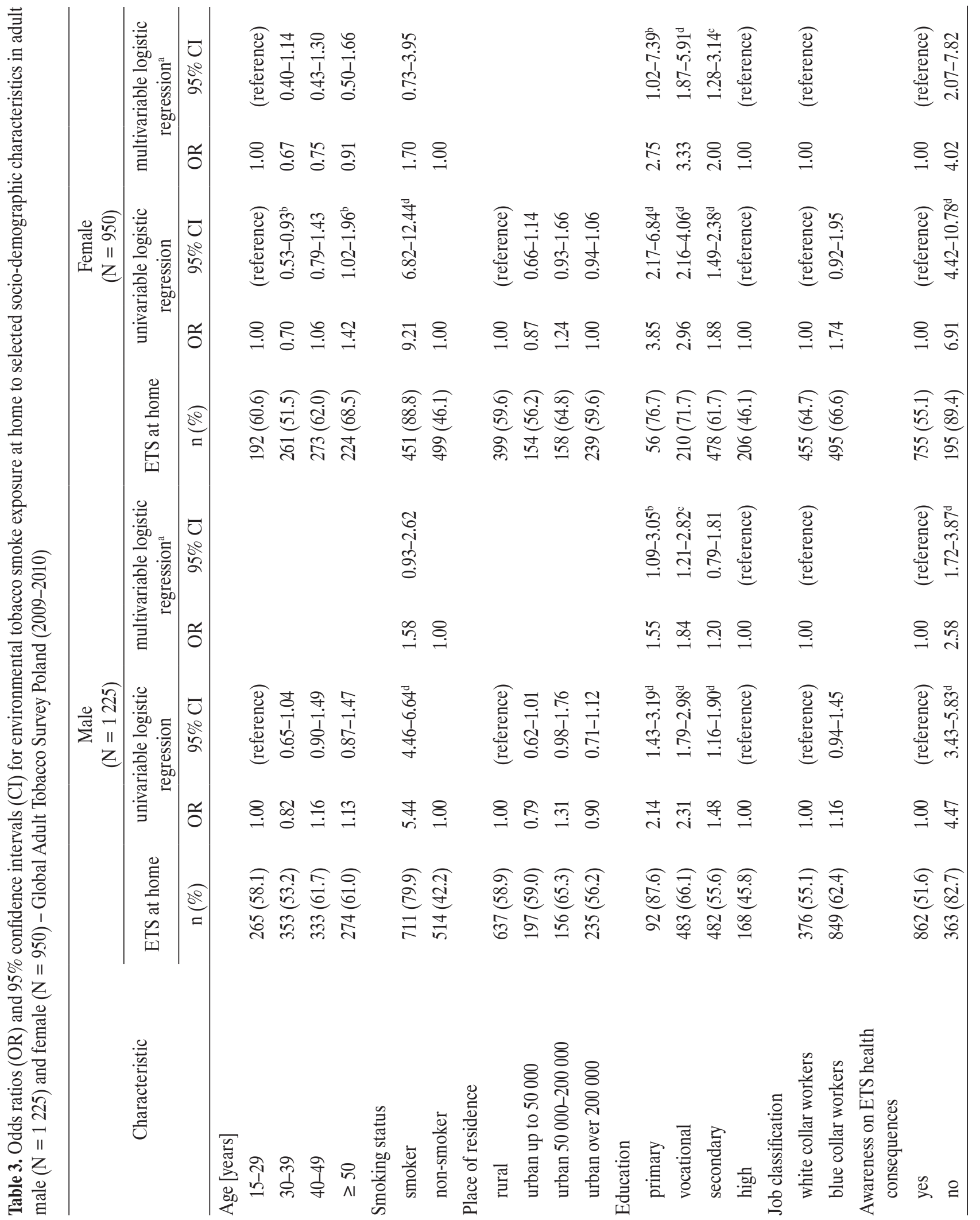




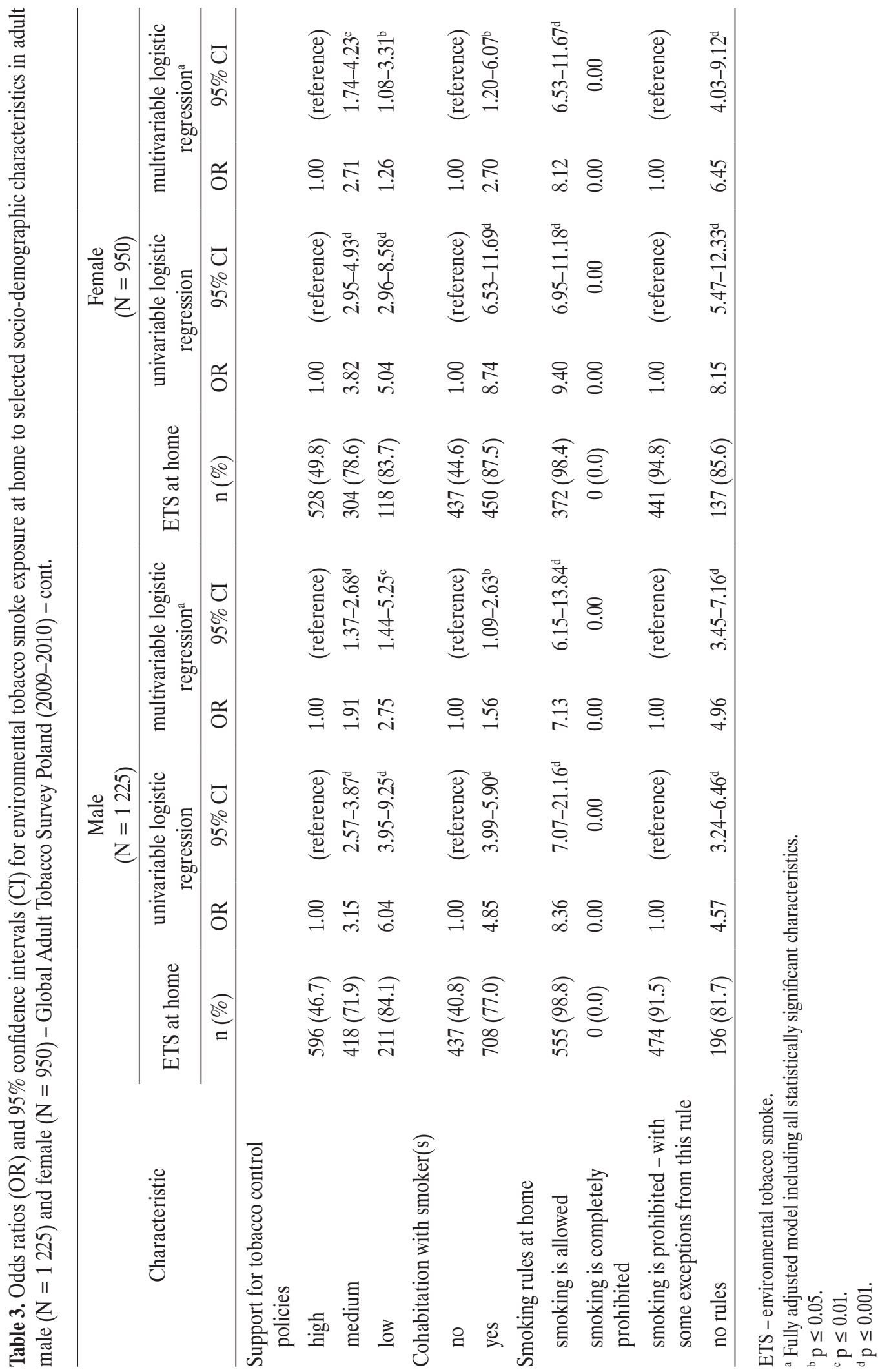


in the home amounted to $54.9 \%$ in Bangladesh, $27.9 \%$ in Brazil, 67.3\% in China, 62.5\% in Egypt, $40 \%$ in India, $17.3 \%$ in Mexico, $54.4 \%$ in the Philippines, $34.7 \%$ in Russia, $33.2 \%$ in Thailand, $56.3 \%$ in Turkey, $23.5 \%$ in Ukraine, $34 \%$ in Uruguay, and $73.1 \%$ in Vietnam. These figures place Poland among the low-middle income countries with medium to high prevalence of the ETS exposure. Nevertheless, compared to high income countries like the United States, prevalence of the residential ETS in Poland was approximately 10 times higher (59\%) than the one found in the US (6\%) [14]. This probably reflects differences in comprehensiveness of tobacco control measures implemented in those countries and social approval for smoking.

Another aspect may be the implementation of countryspecific interventions and policies with special focus on smoke-free public places and adopting 100\% smokefree homes. It should be also underlined that among all respondents who work in an indoor area outside home, the exposure to the ETS in the workplace amounted to $33.6 \%$ in Poland. In 6 out of the 14 countries studied by King et al., the ETS exposure at home was significantly greater among males than females (Bangladesh, Brazil, Philippines, Thailand, Uruguay and Vietnam) [13]. In Poland, we did not find such associations among overall population or economically active residents.

However, similarly to other studies we noticed significantly higher prevalence of the residential ETS exposure among lower educated groups as compared to the population with high educational attainment, those not aware of the ETS dangers and respondents declaring low to medium support for tobacco control policies [14]. These 3 associates appear to be closely correlated. Firstly, these findings may be due to the higher rates of cigarette smoking among low educated groups, cultural factors related to the social approval of smoking, or differences in receptivity toward tobacco-related health messages and understanding of the health hazards associated with the ETS exposure and associated support for tobacco control policies [15-17]. Health knowledge seems to be one of the most important factors limiting the residential ETS exposure.

On the other hand, we noticed that prevalence of the residential ETS exposure was significantly lower among respondents protected by voluntary smoking restrictions at home. This result is consistent with other cross-sectional, environmental studies displaying that smoke-free homes have substantially lower levels of the ETS constituents than those, in which smoking is permitted $[14,18]$.

In this light, it was disturbing that the low prevalence of $100 \%$ smoke-free homes were only adopted by $37.1 \%$ of study participants in comparison to $81.1 \%$ in US [13]. Smoking bans are mainly instituted to protect non-smokers and to decrease overall exposure to the ETS [19]. However, Zhu et al. in his report indicated that they also increased quitting among smokers and prevent relapse among former smokers [19]. Some studies showed that when workplaces implement such policies, people adopt similar policies at home, and effects of smoke-free homes on cessation are even more consistent than those of worksites. This is partly because this data is correlational. Worksite policies are imposed, while home bans may reflect smokers' own motivation to quit [19]. Smoke-free homes should be promoted in our country also to help smokers quit, while cessation services are limited. In Poland there is a need for further studies to understand determinants of voluntarily adopting smoke-free home rules and efforts to improve this situation as well.

\section{Study limitations and strengths}

The study was carried out using a questionnaire. Implementing a questionnaire has many advantages, including the following: a low cost method, the ease of obtaining data with rapid assessment. Unfortunately, the results of the tests depend largely on the reliability of the stated answer. The main drawbacks in obtaining answers about 
smoking or the ETS may be the recall bias - forgetting the important facts, a reluctance to disclose information, the sense of shame associated with admitting to inappropriate behavior and fear of negative evaluation. Such proceedings may lead to underestimation of smoking or exposure to environmental tobacco smoke. The health effects of the exposure to environmental tobacco smoke depend on several factors, among which the most important are: the number of smokers in the room, the number of cigarettes smoked by those persons and the duration of exposure.

Unfortunately the GATS questionnaire does not allow to carefully measure those parameters. The best method to evaluate the extent of exposure to tobacco smoke is to conduct an additional study measuring markers or biomarkers including measuring carbon monoxide in exhaled air and the level of cotinine in saliva, blood, urine and hair $[20,21]$. The data presented in this paper has not been verified by means of objective measures, biomarkers. But due to high costs and time-consuming procedures, such methods are not widely used for huge population surveys. Moreover, the need to collect saliva, urine or blood for biomarker analysis may increase the number of refusals and lead to non-participation bias. In this light, questionnaires seem to be relatively cost-effective, easy to gather, allow approaching a high number of respondents, and are found to be valid tools in most epidemiological studies [22].

Strengths of this study include determining the frequency of anyone smoking inside the respondent's home for example visitors not only originating from the same household. Moreover, the GATS is a countrywide, representative household survey of adults 15 years of age or older using a standard core survey, sample design, and data collection and management procedures that were revised and approved by international experts. However the GATS covered data on non-institutionalized individuals, so the data regarding the ETS exposure among institutionalized subpopulation is missing. Nonetheless, to the best of our knowledge the GATS delivered probably the most valid and the most recent figures existing on smoking and the ETS exposure in Poland [8].

\section{CONCLUSIONS}

According to the World Health Organization there is no risk-free level of the ETS, implementing and enforcing comprehensive smoke-free policies in all workplaces and public places is the effective way to protect the population from the harmful effects of the ETS exposure $[23,24]$. However, decreasing social acceptance of smoking in presence of other people, non-smokers, children, pregnant women and encourage adopting voluntary smoke-free rules at home might decrease the ETS exposure and reduce related risks to health of population of Poles. Considering this, expanding the information on the risk of exposure to environmental tobacco smoke at home, and putting smoke free home rules into practice are of significant public health importance [25]. Increasing the awareness on these issues is of key significance to both nongovernmental organizations involved in tobacco control and policy makers for developing and implementing more effective smoking programs and interventions. Educational activities as well as local or national mass media campaigns are among very important tools to raise awareness on the adverse health effects of smoking. In Poland, there is a common perception that health professionals are not engaged in consulting on the ETS risks. But following experiences from other countries, physicians should advise their patients about dangers of the ETS. Text and pictorial warnings on cigarette packs are also an important component of elevating awareness of the harmfulness of tobacco smoke.

The tobacco control efforts to decrease the ETS, including the home ETS exposure should be focused on the entire population of Poles, in particular on high risk subpopulations. 


\section{ACKNOWLEDGMENTS}

We would like to thank the representatives of the Global Adult Tobacco Survey Scientific Committee (Poland) including: Professor Bolesław Samoliński (Medical University, Warszawa), Professor Witold Zatoński (Cancer Centre and Institute of Oncology, Warszawa), Dr. Przemysław Biliński (Chief Sanitary Inspector, Warszawa), as well as members of the Technical and Survey Staff Team, and our Partners from the World Health Organization (Dr. Lubna Bhatti, Dr. Sameer Pujari), Centers for Disease Control and Prevention (Dr. Samira Asma, Dr. Krishna Mohan Palipudi), CDC Foundation, Johns Hopkins Bloomberg, School of Public Health and the RTI International for their contribution and support. The list of the Study Collaborative Group is available at http://www.mz.gov.pl.

\section{REFERENCES}

1. World Health Organization. Noncommunicable diseases. Fact sheet. Geneva: WHO; 2013 [cited 2014 Nov 17]. Available from: http://www.who.int/mediacentre/factsheets/fs $355 / \mathrm{en} /$.

2. World Health Organization. Action plan for implementation of the European strategy for the prevention and control of NCDs 2012-2016. Copenhagen: WHO; 2012.

3. European Commission - Directorate-General for Health and Consumers. Tobacco: Introduction [cited 2014 Nov 17]. Available from: http://ec.europa.eu/health/tobacco/introdu ction/index_en.htm.

4. International Agency for Research on Cancer. Tobacco smoke and involuntary smoking. IARC monographs on the evaluation of carcinogenic risks to humans. Volume 83. Lyon: WHO, IARC; 2004.

5. Polańska K, Hanke W, Konieczko K. [Hospitality workers' exposure to environmental tobacco smoke before and after implementation of smoking ban in public places: A review of epidemiological studies]. Med Pr. 2011;62(2):211-24. Polish.

6. Kaleta D, Polańska K, Wojtysiak P, Kozieł A, Kwaśniewska M, Miśkiewicz $\mathrm{P}$, et al. Effective protection from exposure to environmental tobacco smoke in Poland: The World
Health Organization perspective. Int J Occup Med Environ Health. 2010;23(2):123-31, http://dx.doi.org/10.2478/ v10001-010-0014-7.

7. Polańska K, Hanke W, Konieczko K. [Impact of the legislation for smoke-free workplaces on respiratory health in hospitality workers-review of epidemiological studies]. Med Pr. 2011;62(3):297-308. Polish.

8. Kaleta D, Usidame B, Biliński P, Raciborski F, Samoliński B, Wojtyła A, et al. Global Adult Tobacco Survey (GATS) in Poland 2009-2010 - Study strengths, limitations and lessons learned. Ann Agric Environ Med. 2012;19(4):658-63.

9. Włodarczyk A, Raciborski F, Opoczyńska D, Samoliński B; GATS PWG. Daily tobacco smoking patterns in rural and urban areas of Poland - The results of the GATS study. Ann Agric Environ Med. 2013;20(3):588-94.

10. Kaleta D, Makowiec-Dąbrowska T, Dziankowska-Zaborszczyk E, Fronczak A. Prevalence and socio-demographic correlates of daily cigarette smoking in Poland: Results from the Global Adult Tobacco Survey (2009-2010). Int J Occup Med Environ Health. 2012;25(2):126-36, http://dx.doi. org/10.2478/S13382-012-0016-8.

11. Kaleta D, Makowiec-Dąbrowska T, Dziankowska-Zaborszczyk E, Fronczak A. Determinants of heavy smoking: Results from the global adult tobacco survey in Poland (2009-2010). Int J Occup Med Environ Health. 2012;25(1):66-79, http:// dx.doi.org/10.2478/s13382-012-0009-7.

12. Kaleta D, Korytkowski P, Makowiec-Dąbrowska T, Usidame B, Bąk-Romaniszyn L, Fronczak A. Predictors of long-term smoking cessation: Results from the global adult tobacco survey in Poland (2009-2010). BMC Public Health. 2012;12:1020, http://dx.doi.org/10.1186/1471-245812-1020.

13. King BA, Mirza SA, Babb SD; GATS Collaborating Group. A cross-country comparison of secondhand smoke exposure among adults: Findings from the Global Adult Tobacco Survey (GATS). Tob Control. 2013;22(4):e5, http://dx.doi. org/10.1136/tobaccocontrol-2012-050582. Erratum in: Tob Control. 2013;22(5):362. 
14. King BA, Dube SR, Homa DM. Smoke-free rules and secondhand smoke exposure in homes and vehicles among US adults, 2009-2010. Prev Chronic Dis. 2013;10:120218, http://dx.doi.org/http://dx.doi.org/10.5888/pcd10.120218.

15. Willemsen MC, Kiselinova M, Nagelhout GE, Joossens L, Knibbe RA. Concern about passive smoking and tobacco control policies in European countries: An ecological study. BMC Public Health. 2012;12:876, http://dx.doi. org/10.1186/1471-2458-12-876.

16. Siahpush M, McNeill A, Hammond D, Fong GT. Socioeconomic and country variations in knowledge of health risks of tobacco smoking and toxic constituents of smoke: Results from the 2002 International Tobacco Control (ITC) Four Country Survey. Tob Control. 2006;15 Suppl 3:iii65-70, http://dx.doi.org/10.1136/tc.2005.013276.

17. World Health Organization. Systematic review of the link between tobacco and the poverty. Geneva: World Health Organization; 2011.

18. Van Deusen A, Hyland A, Travers MJ, Wang C, Higbee C, King BA, et al. Secondhand smoke and particulate matter exposure in the home. Nicotine Tob Res. 2009;11(6):635-41, http://dx.doi.org/10.1093/ntr/ntp018.

19. Zhu SH, Lee M, Zhuang YL, Gamst A, Wolfson T. Interventions to increase smoking cessation at the population level: How much progress has been made in the last two decades? Tob Control. 2012;21(2):110-8, http:/dx.doi.org/ 10.1136/tobaccocontrol-2011-050371.

20. Jaakkola MS, Jaakkola JJ. Assessment of exposure to environmental tobacco smoke. Eur Respir J. 1997;10(10):238497, http://dx.doi.org/10.1183/09031936.97.10102384.

21. Max W, Sung HY, Shi Y. Who is exposed to secondhand smoke? Self-reported and serum cotinine measured exposure in the U.S., 1999-2006. Int J Environ Res Public Health. 2009;6(5):1633-48, http://dx.doi.org/10.3390/ ijerph6051633.

22. Patrick DL, Cheadle A, Thompson DC, Diehr P, Koepsell T, Kinne S. The validity of self-reported smoking: A review and meta-analysis. Am J Public Health. 1994;84(7):1086-93, http://dx.doi.org/10.2105/AJPH.84.7.1086.

23. World Health Organization. WHO report on the global tobacco epidemic, 2008 - The MPOWER package. Geneva: WHO; 2008.

24. World Health Organization. WHO report on the global tobacco epidemic, 2009. Implementing smoke-free environments. Geneva: WHO; 2009.

25. World Health Organization. WHO report on the global tobacco epidemic, 2011: Warning about the dangers of tobacco. Geneva: WHO; 2011.

This work is available in Open Access model and licensed under a Creative Commons Attribution-NonCommercial 3.0 Poland License - http://creativecommons.org/ licenses/by-nc/3.0/p1/deed.en. 